\title{
Reportagem
}

\section{Fórum IBAS debate gestão de escolas de governo, desenvolvimento de dirigentes e prestação de serviços ao cidadão}

Criado em 2003, em uma reunião do G-8 em Evian (França), o Fórum de Diálogo entre Índia, Brasil e África do Sul - IBAS vem permitindo a cooperação trilateral em diversos setores, com foco no desenvolvimento comercial e administrativo. Para compartilhar experiências e boas práticas de gestão pública no eixo Sul-Sul, bem como atividades de formação de dirigentes e prestação de serviços ao cidadão, foi realizado, de 15 a 19 de setembro de 2008, na Escola Nacional de Administração Pública (ENAP), em Brasília, o "I Seminário Práticas Sul-Sul em Gestão de Escolas de Governo, Desenvolvimento de Dirigentes e Prestação de Serviços ao Cidadão".

A primeira parte das atividades ocorreu em São Paulo, onde as delegações estrangeiras visitaram duas ações no campo da atenção ao cidadão e oferta de serviços públicos - o programa Poupatempo e a iniciativa Fácil-Central de Atendimento ao Cidadão (ver box). Os representantes do IBAS conheceram ainda a Fundação do Desenvolvimento Administrativo (Fundap).

A segunda parte do fórum foi realizada na ENAP e envolveu um intenso debate acerca da capacitação de servidores, da formação de dirigentes e da entrega de serviços de qualidade ao cidadão, apontando para um cenário de trocas de experiências e iniciativas bem-sucedidas. Nas apresentações, painéis e discussões em grupo foi unânime o vislumbre das similaridades de situações enfrentadas, das possibilidades de adaptação e mesmo de reprodução dessas práticas segundo as realidades de cada país. Com isso, o primeiro de uma série de três encontros, que reuniu dirigentes das principais escolas de governo da Índia, Brasil e África do Sul, cumpriu sua missão de abrir a agenda e estruturar ações concretas de compartilhamento de ações.

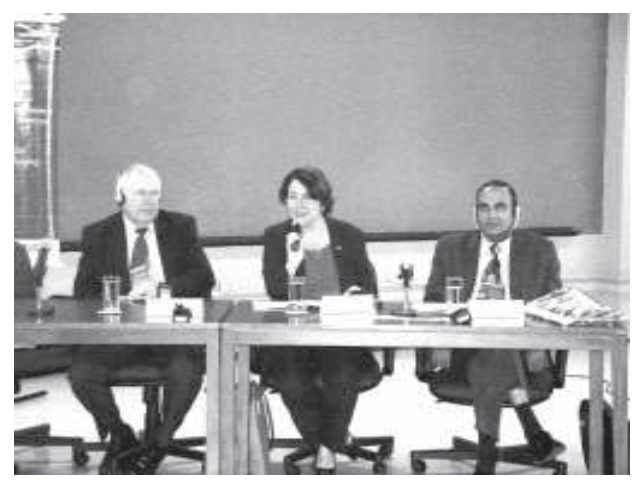

Mark Orkin, Helena Kerr do Amaral e Dhruv Vijai Singh

A formação de dirigentes e servidores engajados e atentos ao atendimento eficiente do cidadão, somada à necessidade de políticas que assegurem o acesso universal aos serviços públicos básicos, são coordenadas que unem e movimentam as ações das escolas de governo presentes no encontro do IBAS. 
Fácil-Central de Atendimento ao Cidadão - Em Guarulhos (SP), a partir de agosto de 2002, com a implantação do Fácil-Central de Atendimento ao Cidadão, foi criada uma porta única para a entrada das solicitações de serviços à prefeitura, garantindo a padronização do atendimento e, principalmente, a melhoria significativa do gerenciamento dessas solicitações, com o desenvolvimento de mecanismos de controle e acompanhamento.

Além da Central de Atendimento localizada no Paço Municipal, foram implantados sete Postos de Atendimento Fácil nos bairros mais afastados do centro, visando à disponibilização de informações e serviços à população, de forma descentralizada. A média de atendimento mensal é de 25 mil pessoas na unidade Bom Clima (Paço Municipal) e de 13 mil nos demais postos espalhados nos bairros. A Rede já realizou cerca de 2,8 milhões de atendimentos.

De modo personalizado, o Fácil oferece mais de 700 serviços, como solicitações para manutenção da cidade - poda de árvore, tapa-buraco, desratização, sinalização etc. -, alvarás, certidões e licenças, informações e pagamentos de tributos, protocolo de documentos, entre outros.

O projeto foi desenvolvido com a participação de todos os órgãos municipais, de forma matricial, e tem sua gestão também coletiva, envolvendo diretamente as secretarias de Administração, Finanças e Desenvolvimento Urbano, o que resultou em profundo impacto na reorganização das secretarias e na incorporação de novas tecnologias.

A prefeitura de Guarulhos optou por valorizar e incentivar a função de atendimento ao público. Para isso, buscou obter os melhores servidores para a função, realizando rigorosa seleção interna, capacitando-os e gratificando-os. Os servidores designados para prestar atendimento ao cidadão têm jornada de trabalho diferenciada e recebem gratificação em seus salários.

Poupatempo - Implantado em 1996 pelo Governo do Estado de São Paulo, o programa passou a reunir, em um único local, vários órgãos e empresas, com o objetivo de facilitar o acesso do cidadão a informações e serviços públicos. Acesso a documentação, a atestados de antecedentes criminais, ao seguro-desemprego e a programas de recolocação no emprego estão entre os mais demandados de um conjunto de cerca de 400 serviços prestados.

O primeiro posto do Poupatempo foi inaugurado em 1997 na Praça do Carmo, próxima à Sé. Com a aprovação social do padrão de atendimento do programa, a iniciativa foi estendida a 11 locais fixos de atendimento no estado de São Paulo e estão em andamento as obras para mais cinco unidades. Além disso, há unidades móveis, que levam os principais serviços à população residente em bairros e municípios distantes dos postos fixos. São as Unidades Itinerantes, que ficam de 3 a 15 dias em cada roteiro, de acordo com a demanda.

Acompanhando a expansão do uso do meio eletrônico, foi criado o e-poupatempo, que disponibiliza e incentiva o acesso a serviços públicos como consulta de débitos de IPVA, DPVAT, multas de trânsito, pontos na $\mathrm{CNH}$ e registro de Boletim de Ocorrência, via internet.

O Poupatempo se tornou um modelo de atendimento para outros órgãos e empresas governamentais, sendo seguido também pela iniciativa privada. Experiências inspiradas nesse programa foram implantadas em Salvador (BA) e em Brasília (DF). Em 2006, uma pesquisa do Ibope revelou que 99\% dos usuários aprovaram o atendimento prestado em São Paulo. A unidade de Guarulhos foi avaliada como a de melhor desempenho, com 99,7\% de atendimento bom ou ótimo.

Com a participação dos principais responsáveis pela implementação das políticas nacionais de capacitação de servidores públicos, três foram os eixos que conduziram as discussões: a democratização e a ampliação da prestação de serviços de qualidade a todos os cidadãos; a importância de as escolas se apropriarem mais e melhor de conceitos que orientam a formação voltada ao desenvolvimento pleno das capacidades para fazer frente ao novo contexto de mundialização, na qual antigas barreiras formais ao conhecimento vêm sendo derrubadas a cada dia; e o debate franco das necessidades de aperfeiçoamento na gestão das escolas de governo 
para enfrentar os novos desafios associados, no caso de Índia e África do Sul, a políticas de massificação da capacitação.

Aproveitando a decisão de aproximar países do hemisfério sul, em estágio de desenvolvimento similar, mas com aspectos políticos, administrativos, geográficos e sociais diversos, os representantes das escolas de governo, especialmente da Índia e da África do Sul, desde as suas apresentações iniciais chamaram a atenção para os desafios que enfrentam na formação de quadros governamentais em contextos de escassez de recursos, mas principalmente de multiplicação dos serviços a serem oferecidos. As escolas da Índia e da África do Sul presentes ao encontro do IBAS são responsáveis pela qualificação de todos os servidores públicos, diferentemente da ENAP, que atua predominantemente na formação de dirigentes e anima a rede de escolas das três esferas de governo.

A democratização e o reconhecimento do direito de cada cidadão ao atendimento de suas necessidades são uma realidade tanto quanto o hiato da capacidade instalada para a prestação de serviços, considerando-se o tamanho da população de cada país, as mudanças de perfil decorrentes de seu envelhecimento, as dificuldades resultantes da extensão geográfica, dos aglomerados urbanos, da insuficiência de infra-estrutura e dos recursos humanos capacitados. Esse ponto de partida acentuou a importância do exercício de escuta das experiências nacionais e do debate sobre as similaridades e as diferenças de contexto e de método de ação utilizados na prestação de serviços dignos, nos objetivos das políticas públicas e na formação de quadros.

Os resultados, no entanto, são promissores, pois, ao lado dos investimentos em estudos de casos setoriais comparativos, apostam, ainda, na troca de experiências, no mútuo assessoramento e no olhar focado na problemática segundo a experiência já mapeada.

\section{Foco no cidadão}

Para erradicar a pobreza e ampliar a igualdade de oportunidades, em um contexto político e democrático, a Índia vem assumindo, há cerca de seis décadas, um movimento de desenvolvimento e crescimento econômico, que inclui maciços investimentos em infra-estrutura e nas redes nacionais de prestação de serviços. Enquanto em 1951 havia apenas 725 instituições públicas de saúde e 215 mil escolas primárias, hoje são mais de $163 \mathrm{mil}$ unidades de saúde e 641 mil estabelecimentos de educação infantil. Nesse contexto, o secretário-adjunto do Departamento de Reformas Administrativas e Reclamações Públicas da Índia, Dhruv Vijai Singh, expôs que as "democracias somente se sustentam segundo a satisfação dos cidadãos e a eficiência na oferta dos serviços públicos”.

O dirigente indiano enfatizou que, além da prestação de qualidade, é importante a constituição e a continuidade de políticas públicas sempre em consonância com as demandas de uma população numerosa e diversificada, com atenção às parcelas mais carentes, em especial aquelas que vivem em áreas rurais. "Devemos estar atentos ao que o cidadão quer e precisa, não ao que o governo acha que o povo precisa". Destacou que a Índia é "uma terra de contrastes" e, por isso, é fundamental "direcionar as políticas aos segmentos mais pobres, pois os ricos têm poder de compra e a classe média já é assistida".

Singh também ressaltou a ênfase do governo indiano na promoção da política nacional de capacitação, investindo em uma 
formação continuada, de maneira descentralizada e segundo as especificidades dos vilarejos, cidades, regiões. "Nossa visão é a de que o governo não é pai dos cidadãos. Esse é um pensamento antigo, uma mentalidade colonial que deve ser superada". Singh apontou ainda a necessidade de o cidadão se apropriar das informações de interesse público.

Segundo a avaliação de Mohammed Abid, professor da Administrative Staff College of India - ASCI, "os debates acentuaram que nosso desafio comum são os números: temos, na Índia, um setor público enorme para atender às demandas de um vasto país com população volumosa. Nossa missão é capacitar e desenvolver os servidores públicos seniores, mas temos que prestar mais atenção também aos funcionários que trabalham com atendimento ao cidadão, especialmente nos setores de saúde e educação".

\section{Aprendizado pela ação}

Considerado como promissor e emblemático no campo que aponta para um cenário de educação continuada e permanente, o contexto da capacitação do serviço público na África do Sul foi apresentado pelo vice-diretor do Public Administration Leadership and a Management Academy (Palama), Rufus Mmutlana, a partir do projeto Khaedu, palavra que significa "desafio" em sesotho.

Desenvolvido em 2004 para capacitar gestores na prestação de serviços, a grande ênfase do programa é o aprendizado pela ação - action learning - baseado no trabalho em equipe e na ampla utilização de estudos de caso e pouca teoria (aulas formais). Tratar com eficiência o desafio do fornecimento de serviços é o propósito da iniciativa. Rufus explica que a dinâmica, envolvendo cerca de 2.500 gestores no país, mas na expectativa de sensibilizar cerca de oito mil em mais três anos, tem colaborado para diminuir a morosidade e a burocracia, otimizando os serviços públicos e aumentando a satisfação do usuário.

O projeto Khaedu, carro-chefe na estrutura programática de sua escola de governo, que é conhecida como Palama (Academia de Gestão de Liderança na Administração Pública), representa uma abordagem inovadora de aprendizado, expressa na identificação de habilidades e no engajamento dos servidores envolvidos em projetos-piloto de grande alcance social. De acordo com Mmutlana, "em vez de termos pessoas sentadas em sala de aula ouvindo um professor, trabalhamos com fatos reais no local do trabalho. Os próprios servidores apresentam propostas para resolver problemas específicos, considerando suas respectivas experiências já adquiridas, melhorando, assim, a oferta de serviços públicos".

\section{Inclusão Digital}

Tanto os problemas enfrentados pela Índia quanto pela África do Sul são conhecidos pelo Brasil. O Governo Federal brasileiro adotou a inclusão digital como instrumento fundamental de garantia e acesso a serviços e informações, conferindo transparência às ações de governo e visibilidade aos direitos dos cidadãos. $\mathrm{O}$ software livre e a internet como mecanismos de superação dos problemas regionais e de garantia do acesso aos serviços por parte dos cidadãos, como eixo estratégico de desenvolvimento, foram abordados pelo secretário-adjunto de Logística e Tecnologia da Informação do Ministério do Planejamento, Orçamento e Gestão, Rodrigo Assumpção. "As tecnologias de informação e comunicação 
são hoje o principal meio de produzir e organizar conhecimento, colocando-o a serviço dos interesses públicos". Investindo-se no governo eletrônico é possível aumentar rapidamente a capacidade de gestão, a transparência dos investimentos, dando celeridade ao atendimento ao cidadão e evitando qualquer sorte de paternalismo.

$\mathrm{Na}$ chamada "sociedade do conhecimento", Rodrigo Assumpção ressaltou ainda que "a inclusão digital é uma política pública constituída para assegurar os direitos de cidadania e de desenvolvimento regional e nacional". Segundo o secretário-adjunto, o Governo Federal brasileiro já implantou cinco mil telecentros comunitários voltados à oferta de serviços públicos, além de investir na informatização das escolas públicas e no treinamento de pessoal. Em sua avaliação, "a tecnologia não significa a diminuição de recursos humanos, mas sim de remanejamento e reaproveitamento de postos de trabalho".

Para que as estratégias de prestação de serviços e de solução de problemas possam cumprir seu papel, a capacitação dos servidores e os focos escolhidos pelas escolas configuraram dois aspectos fundamentais que orientaram as discussões no IBAS.

\section{Capacity Development}

A importância de ampliar o conceito que orienta as políticas de capacitação, inserindo-as no campo da educação permanente, movimentou parte das reflexões acerca do papel das escolas de governo no aperfeiçoamento das políticas de desenvolvimento de servidores.

Além de desdobrar e iluminar a estratégia do action learning, a reflexão, proposta pelo sociólogo e economista Carlos Lopes, diretor-executivo do Instituto das Nações Unidas para Formação e Pesquisa (Unitar), constituiu pano de fundo para o debate da transformação na ação das escolas de governo. Para Lopes, é fundamental superar o conceito de construir capacidades (capacity building) - que busca a capacitação do servidor pela criação e estruturação de competências dedicadas a um determinado momento e problema para alcançar o desenvolvimento de capacidades (capacity development), o que coloca no centro a formação permanente do servidor e a necessidade de que a superação de novos e velhos problemas ocorra de forma criativa e inovadora. Em sua apresentação, Lopes afirmou que "a tendência deve ser investir no sistema de formação e capacitação inserido em um contexto mais amplo, sob a perspectiva de reter capacidades para ajustá-las ao aproveitamento das instituições e da sociedade".

De acordo com o diretor da Unitar, para viabilizar um bom desenvolvimento de capacidades, as escolas de governo devem conjugar três instâncias: atenção à educação e à qualificação individual; capacidade institucional de aproveitamento de cada competência; e alinhamento dessas variáveis no contexto social. Para Lopes, "não pode haver desenvolvimento sem transformação, e é preciso dispor de habilidades específicas para lidar com os problemas dos países emergentes". Segundo ele, "não é obrigação do governo prover todos os serviços, mas deve assegurar que estes sejam oferecidos". Cita como princípios-chave para um efetivo e eficiente gerenciamento público a importância de empoderaras comunidades para resolver seus próprios problemas, encorajando a competitividade e a descentralização da autoridade, assim como os exemplos apresentados pela Índia e África do Sul e algumas iniciativas já conhecidas da realidade brasileira. 


\section{Escolas de governo}

É no contexto de ampliação desse conceito de capacitação que se insere a estratégia da ENAP de capacitação de dirigentes visando atender não apenas às demandas dos indivíduos, mas principalmente às necessidades das organizações governamentais. Com isso, a capacitação dos servidores estará, cada vez mais, referenciada na estratégia institucional de superação das dificuldades organizacionais, conferindo, assim, efetividade ao esforço de aprendizagem por meio da incorporação dos conhecimentos adquiridos à prática. Na ENAP, esse caminho se aplica não apenas às atividades pedagógicas presenciais, mas também às ações de educação a distância, onde, progressivamente, as turmas são fechadas e dedicadas a grupos de uma única instituição, potencializando, dessa maneira, a utilização dos conhecimentos entre os integrantes da turma e a sua interação com o formador.

Foi debatida ainda a necessidade de mudança nos temas a serem ensinados, direcionando os esforços para resolver problemas que envolvem, entre outros, articulação intergovernamental, novas necessidades do federalismo, sensibilidade para conhecimento da realidade local, gerenciamento de crises e solução negociada de conflitos. Vale lembrar que há servidores federais em todas as unidades da federação, que também precisam saber como agir para que os projetos federais assumam efetividade local e regional.

$\mathrm{Na}$ África do Sul, as dificuldades enfrentadas são similares às descritas pelo Brasil e pela Índia. É importante, porém, destacar a busca pela formação de mulheres e homens negros para os cargos de direção. Em que pesem as novas legislações assegurando postos de trabalho para a população negra, formar pessoas com a sensibilidade para escutar as dificuldades do cidadão e ainda superar seus próprios preconceitos em relação à diversidade torna claro um desafio, que sendo comum aos dois outros países, não é tão visibilizado pelas políticas de formação e de promoção dos servidores públicos. Destaque-se que diversidade é entendida aqui não apenas como as diferenças associadas a gênero, raça ou etnia, mas também as referentes às necessidades de pessoas com deficiências físicas, com mais idade ou mesmo com menos escolaridade, aumentando, assim, o amplo leque de situações de potencial e efetiva discriminação.

O sucesso das políticas de formação pelo desenvolvimento de capacidades envolve outro aspecto crucial: os três países precisam fazê-lo em escalas muito grandes em curtos espaços de tempo para dar efetividade às suas metas de atenção aos cidadãos. Segundo a avaliação de Mohammed A. Abid, professor da ASCI, na Índia, "nosso maior desafio são os números: temos um setor público enorme para atender às demandas de um vasto país com população volumosa (na Índia há 1 bilhão de pessoas; no Brasil, 190 milhões; na África do Sul, 43,7 milhões)."

Para massificar a capacitação de servidores, considerados o tamanho e as mudanças de perfil da população, as dificuldades regionais, além da tecnologia, as escolas de governo devem passar a aprofundar seu papel de formadoras de formadores. Por isso é fundamental investir em uma estratégia para assegurar que os formadores locais estejam habilitados a multiplicar e padronizar ações de capacitação. Há iniciativas nesse sentido nos três países, mas ainda insuficientes frente ao desafio vislumbrado.

$\mathrm{Na}$ Índia há programas de capacitação para formadores que envolvem 2.800 
servidores com nível de mestrado, cujos cursos contam, desde 1983, com o apoio da Universidade do Vale do Tâmisa, do Reino Unido. Para Ajay Sawhney, do Ministério de Pessoal da Índia, esses formadores, que vêm trabalhando crescentemente em rede, têm multiplicado sua atuação. Ajay avalia, porém, que isso ainda é insuficiente para atingir a meta de atendimento a todos os cidadãos, com qualidade. Esse desafio tem levado a que as práticas de maior interesse para a Índia envolvam escala e formação de formadores, com a utilização de ferramentas como a educação a distância e atividades mistas de formação.

No Brasil, o programa de parcerias da ENAP com outras escolas e universidades, iniciado em 2003, vem estruturando a padronização de cursos ofertados a servidores federais fora de Brasilia. Essa ação, que agrega bons resultados para a melhoria do padrão das atividades, é, porém, insuficiente, e a Escola já dá indicações de que investirá mais nos próximos anos no campo de apoio e multiplicação de formadores.

\section{Desafios}

As questões de escala na formação de servidores e de formadores sensibilizados para a diversidade e para os contextos locais de desenvolvimento naturalmente apareceram como mais um desafio estratégico a ser considerado, passível de apoio mútuo por parte das escolas, que buscam uma solução adequada.

O reconhecimento de que novas estratégias precisam ser implementadas é uma realidade antevista e esperada pelas escolas participantes do encontro na ENAP. Em todos os casos, foi identificada a necessidade de um maior contingente de pessoas envolvidas com a formação. Muitas indicações apontaram para o fato de que o perfil dessas equipes tem de ser multidisciplinar, afeito à diversidade de indivíduos que exercem seus direitos de cidadania e à necessidade de melhoria na qualidade da resposta que os serviços públicos devem oferecer ao cidadão. Soluções inovadoras precisam ser encontradas para que os recursos de capacitação, escassos em todos os países, sejam otimizados e direcionados para esse esforço de acesso e eficiência no atendimento prestado à sociedade.

Como resultado imediato da cooperação, foi constituída uma comunidade virtual, desenvolvida pela ENAP em ambiente software livre, para fomentar a interlocução e a troca de experiências e boas práticas. O portal, construído a partir da plataforma Moodle (Modular Object Oriented Development Learning Enviroment), já reúne documentos e apresentações dos representantes do IBAS, configurando, ainda, um espaço de preparação do próximo encontro.

Tanto as especificidades geográficas quanto os diferentes avanços associados à democracia e políticas públicas em cada país foram ressaltados nas exposições das atividades de formação e capacitação das escolas pelo pesquisador e consultor em serviços de governança e gerência no setor público, Victor Ayeni, do Reino Unido, responsável pela consolidação do documento final desse seminário. Em

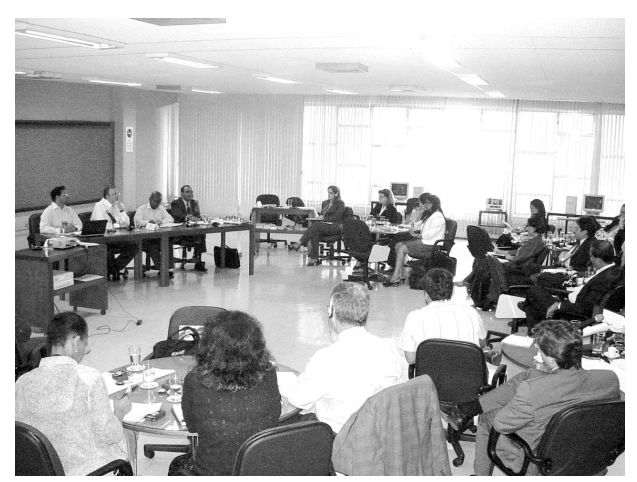


termos mais amplos, Ayeni destacou a importância de se trocar experiências em educação e capacitação; de se incentivar, no âmbito das escolas, a relação com profissionais não acadêmicos; e de contribuir para superar os grandes desafios de governança, como a redução da pobreza e a promoção de desenvolvimento social. Outros pontos levantados foram a importância da busca de resoluções de pontos críticos e a necessidade de foco a partir de estudos comparativos e troca das boas práticas que envolvem "documentar o que se sabe, o que se fez de certo e onde se falhou, além de disseminar as experiências".

No encerramento do encontro, a presidente da ENAP, Helena Kerr do Amaral, avaliou que "além da questão da prestação orientada ao cidadão e da busca da igualdade social, essa cooperação SulSul fortalece a Escola e os servidores brasileiros que serão capacitados". E, em relação às especificidades de cada país e aos problemas graves enfrentados por essas nações, considerou que "do respeito à diversidade que caracteriza nossos países podemos construir um mundo melhor". Para o secretário Dhruv Vijai Singh, “ao final desse encontro inicial, temos uma idéia da direção que os próximos encontros seguirão. E está cada vez mais claro como esse processo contribuirá para melhorarmos nossas escolas de governo, nossas práticas de capacitação e de desenvolvimento de competências a partir de nosso foco maior - o cidadão".
Mark Orkin, da África do Sul, diretorgeral da Palama, afirmou que "assim como o diálogo com as nações do G-8 é importante, é nosso dever ampliar a conexão com os países do Sul-Sul, fortalecendo nosso compromisso como agentes públicos. Em nossos países, não basta ser um servidor público. É preciso ser um agente de desenvolvimento num país em desenvolvimento".

O encerramento do Seminário foi selado com uma agenda de trabalho presencial e virtual, envolvendo a utilização do conhecimento acumulado em cada uma das escolas para apoiar as demais no crescimento de ações que compreendem educação a distância, reprodução de experiências bem-sucedidas de action learning, de ações junto a pequenas comunidades e da prestação de múltiplos serviços, como o Fácil-Central de Atendimento ao Cidadão e o Poupatempo, bem como outras iniciativas de âmbito estadual ou municipal em curso no Brasil. Nos próximos meses, as escolas esperam dedicar-se a uma discussão mais apurada com o objetivo de definir estratégias passíveis de implementação para fazer frente ao problema da massificação da capacitação de servidores, tema que afeta a Rede de Escolas de Governo no Brasil, cabendo à ENAP articular o conhecimento desenvolvido e as experiências nacionais e internacionais. Sem dúvida, um promissor começo que poderá legar, a médio prazo, bons frutos aos três países. 